\title{
A EPIFANIA NOS TANKAS DE WILSON BUENO
}

\section{THE EPIPHANY IN WILSON BUENO' TANKAS}

\author{
Cícera Rosa Segredo Yamamoto ${ }^{1}$ \\ UFMS - Universidade Federal de Mato Grosso do Sul \\ Rauer Ribeiro Rodrigues ${ }^{2}$ \\ UFMS - Universidade Federal de Mato Grosso do Sul \\ Kelcilene Grácia-Rodrigues ${ }^{3}$ \\ UFMS - Universidade Federal de Mato Grosso do Sul
}

\begin{abstract}
RESUMO: O objetivo deste trabalho é estudar a epifania nos tankas de Wilson Bueno. A composição poética tanka surgiu no Japão, por volta do ano 710 e é constituída por 31 sílabas distribuídas em cinco versos com 5-7-5-7-7 sílabas. Sua origem está no waka, forma poética que "cantava" trechos históricos e legendários da vida do povo nipônico. Wilson Bueno buscou, nos tankas, a inspiração para compor os poemas de dois de seus livros: Pequeno tratado de brinquedos (1996) e Pincel de Kyoto (2008). O presente artigo tem como objetivo mostrar a configuração da tradição milenar do tanka e o resgate dessa poesia tradicional, transfigurada e personalizada de forma moderna, na produção literária de Wilson Bueno, pois o escritor incorpora, em seus tankas, estratégias literárias de autores ocidentais do século XX, em especial a epifania, conceito proposto por James Joyce em Stephen Hero, romance escrito nos primeiros anos do século XX.
\end{abstract}

PALAVRAS-CHAVE: epifania; ocidente; oriente; poesia brasileira.

ABSTRACT: The objective of this work is to study the epiphany in Wilson Bueno's tankas. The poetic composition of tanka appeared in Japan, around the year 710, and it is constituted by 31 syllables distributed into five verses with 5-7-5-7-7. Its origin is in the waka, poetic form that sang historical and legendary excerpts of the Japanese people's lives. Wilson Bueno searched in the tankas the inspiration to compose the poems of two of his books: Pequeno tratado de brinquedos (1996) and Pincel de Kyoto (2008). The present article has the objective of showing the configuration of the tanka's millennial tradition and the rescue of this traditional poetry, transfigured and personalized in a modern way in Wilson Bueno's literary production, because the writer incorporates in his tankas literary strategies of the twentieth century western authors, especially the epiphany, concept proposed by James Joyce in Stephen Hero, romance written in the first years of the twentieth century.

\footnotetext{
${ }^{1}$ Mestranda do Programa de Pós-Graduação em Letras - Estudos Literários da Universidade Federal de Mato Grosso do Sul (UFMS), do Campus de Três Lagoas; bolsista Capes; yamacissa @ hotmail.com.

${ }^{2}$ Rauer Ribeiro Rodrigues é professor de Literatura Brasileira na UFMS, doutor em Estudos Literários pela UNESP de Araraquara e professor no Mestrado em Letras da UFMS, em Três Lagoas, onde coordena o Grupo de Pesquisa Luiz Vilela (ver gpluizvilela.blogspot.com); rauer.rauer@uol.com.br.

${ }^{3}$ Kelcilene Grácia-Rodrigues é doutora em Estudos Literários pela UNESP de Araraquara e professora de literatura brasileira na UFMS, onde é Coordenadora do Mestrado em Letras do Campus de Três Lagoas; participa do GT Texto Poético da ANPOLL; kelcilenegracia@uol.com.br.
}

Disponível em: http://seer.fclar.unesp.br/casa 
KEYWORDS: epiphany; occident; east; Brazilian poetry.

\section{Introdução}

Este trabalho tem por objetivo analisar a epifania em poemas com a forma de tanka dos livros Pincel de Kyoto (2008) e Pequeno tratado de brinquedos (1996), de Wilson Bueno. Para tanto, refletiremos sobre o universo da poética do tanka, o conceito de epifania e qual a importância da epifania desses dois livros de Wilson Bueno.

Desde criança, Wilson Bueno, nascido em Jaguapitã, no Paraná, cidade onde muitos japoneses se instalaram quando vieram para o Brasil, teve contato com a cultura japonesa. Quando o escritor mudou-se para Curitiba, continuou lendo autores da literatura japonesa e também conviveu com muitos japoneses. Em entrevista a Marília Kubota (BUENO, 2009), o escritor enfatiza que a convivência com os nipônicos lhe deu a oportunidade de ter acesso a diversas obras literárias orientais que exerceram profunda importância na sua formação e influenciaram as suas primeiras iluminações literárias. Em especial, propiciou-lhe escrever tankas, forma poética originária da cultura nipônica.

O tanka é constituído por 31 sílabas distribuídas em cinco versos com 5-7-5-77 sílabas. Sua origem está no waka - termo genérico para designar a poesia aristocrata do Japão, constituída de algumas diferenças nas sílaba - uma forma poética em que se "cantavam" trechos históricos e legendários da vida do povo nipônico. A palavra foi inventada durante o período $\mathrm{Heian}^{4}$ para diferenciá-la da poesia nativa dos chineses, o que a fez abarcar diferentes estilos. Sua evolução aponta para as seguintes mudanças em sua constituição silábica: o thôca (43 sílabas), denominado como poema longo, depois o sendôca (38 sílabas). Com o passar do tempo, aos poucos, foi se transformando em poesias mais curtas, denominadas tankas (31 sílabas em versos de 5-7-5-7-7 sílabas).

De acordo com Franchetti, Doi e Dantas (1996), os três primeiros versos 5-7-5 recebem denominação de kami-no-ku (estrofe de cima), e os dois últimos versos 7-7 são nomeados de shimo-no-ku (estrofe de baixo). Essa é a estrutura básica que compõe os tankas, corolário das modificações que tal forma poética sofreu com o passar dos séculos.

$\mathrm{O}$ tema dos tankas se define a partir das coisas simples do cotidiano, sendo poema de fácil compreensão. O poeta que compõe o tanka deve estar sempre atento para captar a instantaneidade, como se estivesse com uma câmara na mão pronta para apertar o flash.

Assim, considerando na diacronia o que é o tanka, sua origem e constituição, este trabalho objetiva analisar poemas de dois livros de Wilson Bueno, visando a explorar a peculiar junção que o escritor faz de uma forma oriental de longa tradição com uma recente estratégia discursiva da literatura ocidental.

Primeiramente, o artigo apresenta dados biográficos de Wilson Bueno; em seguida, discorre sobre o conceito de epifania e, por fim, mostra como se processa a epifania e qual a sua relevância na obra poética de Wilson Bueno, em específico em seus poemas tankas.

\section{Wilson Bueno}

Wilson Bueno (Jaguapitã, Paraná, 1949 - Curitiba, 2010) foi, durante oito anos, editor, em Curitiba, do premiado periódico literário Nicolau, considerado, na época, como o melhor jornal cultural do Brasil pela Associação Paulista dos Críticos de Artes,

\footnotetext{
${ }^{4}$ A literatura japonesa é dividida conforme o período histórico, denominado de acordo com o imperador.
} 
inclusive alcançando reconhecimento internacional. Wilson Bueno graduou-se em jornalismo na USP, obteve especialização em comunicação rural e em jornalismo científico, tendo ainda feito mestrado e doutorado em comunicação pela USP. ${ }^{5}$

Publicou as seguintes obras: Bolero's Bar (Curitiba: Criar, 1986), Manual de zoofilia (Florianópolis: Noa Noa, 1991), Mar paraguaio (São Paulo: Iluminuras 1992), Cristal (São Paulo: Siciliano, 1995), Pequeno tratado de brinquedos (São Paulo: Iluminuras, 1996), Meu tio Roseno, a cavalo (São Paulo: 34, 2000), Amar-te a ti nem sei se com carícias (São Paulo: Planeta, 2004), Cachorros do céu (São Paulo: Planeta, 2005), A copista de Kafka (São Paulo: Planeta, 2007), Pincel de Kyoto (São Paulo: Lumme, 2008). Também foi grande sua atuação em revistas e jornais, e destacou-se como colaborador do jornal $O$ Estado de $S$. Paulo.

Ana Paula de Carvalho (2010), em $O$ Globo, informa sobre Wilson Bueno: "Considerado um dos maiores escritores brasileiros contemporâneos, Bueno foi finalista do Prêmio Jabuti em 2001 com o livro Meu tio Roseno, a Cavalo e também teve suas obras publicadas no Chile, Cuba, México, Argentina e Cuba". Além disso, escreveu para vários jornais brasileiros e assinava mensalmente uma coluna para o site Trópico.

$\mathrm{O}$ escritor tem sido objeto de estudo de muitos pesquisadores, e sua obra é estudada em várias universidades do Brasil, o que demonstra sua importância para a literatura brasileira. Isso decorre do fato de Wilson Bueno possuir um estilo inovador e inusitado que se evidencia em sua forma de escrever e de lidar com a linguagem. O escritor, aliás, reconhece isso em uma entrevista:

Sim, você tem toda razão: sou um reescritor por excelência, tanto pela artesania obsessivo-flaubertiana do meu processo de criação propriamente dito quanto pelo reandar caminhos já andados movido por novos pés e quiçá, outros olhares. Reolho, reescuto, releio as coisas [...]. (BUENO, 2009, p. 2).

É relevante salientar que essa forma de reescrita é uma recorrência na arte de Wilson Bueno como, por exemplo, em Amar-te a ti nem sei se com carícias e A copista de $K a f k a,{ }^{6}$ entre outros de seus trabalhos. Entretanto sua escrita é muito mais do que uma constante forma de reescrever - é como lapidar uma pedra bruta, tornando-a preciosa, conforme destaca Ricardo Lima ao falar sobre o escritor:

\begin{abstract}
A habilidade de Wilson Bueno mora aí, na provocação da surpresa através do enigma e do fantasma, e não apenas ao leitor, mas a si mesmo, ao seu gesto como escritura. Não à toa Wilson insiste sempre em desafiar a sua própria narrativa, para que ela se veja também afetada por suas sombras, suas assombrações. Tome-se de pronto, por exemplo, o que conseguiu escavar nas narrativas mínimas do Manual de Zoofilia e de Jardim Zoológico, nas maneiras litúrgicas e empoladas de um começo de século XX desaprumado em Amar-te a ti nem sei se com carícias ou na vereda pantanosa dos idos de 1940, quando "tio Roseno, Rosemundo, Rosevaldo, montava o seu Zaino brioso, procurando pela bugra Dorói”, em Meu Tio Roseno, a cavalo. (LIMA, 2007, p. 4).
\end{abstract}

\footnotetext{
${ }^{5}$ Dados biobibliográficos em: < http://www2.metodista.br/unesco/PCLA/revista13/perfis\%2013-1.htm >, acesso em 30 set. 2011.

${ }^{6}$ A propósito de reescrita em Wilson Bueno, ver o trabalho de Geovana Quinalha de Oliveira (2007), o de Juliana Aparecida Sterse Viana (2009) e o de Rauer (2008).
} 
Segundo Lima, o moderno em sua criação estaria nas mudanças de estilo, na flexibilidade perante a linguagem e mesmo na construção da estrutura da própria narrativa. Wilson Bueno, em entrevista a Rodrigo de Souza Leão, explicita:

\section{Qual o papel do escritor na sociedade?}

Nossa função, penso, é não deixar nunca [que] a superfície chapada das coisas vigore, ou se revigore. O compromisso do escritor é com o lúdico, com o inútil essencial da vida. Brincantes e mágicos, feiticeiros e inventores, os escritores temos que estar atentos para que a linguagem não congele em fórmulas exitosas. Necessário o gosto e o gozo do texto sempre novo, o ar, a nova aragem. Numa sociedade que tende à estagnação da linguagem, o escritor é aquele demônio capaz de revirar o tempo todo, revirar esta mesma linguagem para que ela não pereça nem morra de preguiça ou pelo uso congelado de sua repetência. O olhar do escritor tem que estar sempre invariavelmente na direção do horizonte... Quem se dedica à busca, está sempre encontrando. (BUENO, 2002, p. 2).

Nessa entrevista, Bueno adianta o que Lima posteriormente desenvolveu: o escritor deve ser um não conformista, não deve estagnar, deve sempre revigorar seus textos, dando a eles "novas roupagens", nova forma de escrever; Bueno deixa claro que é preciso inovar e não se repetir com textos comuns, que não prendem e não surpreendem. Devido a essa intenção, Wilson Bueno é um escritor bastante eclético, e sua obra abrange grande diversidade de propostas discursivas e de gênero. Talvez por isso, pode-se dizer que esse seu modo irreverente de escrita coloque-o - em tempos tão acomodatícios - como "ponta de lança" para uma nova postura perante a forma de escrever, particularmente no que diz respeito à poesia.

A nosso ver, Wilson Bueno procura surpreender o leitor como escritor nos dois livros em que trabalha com tankas. Essas obras têm sua essência no waka, que é uma forma poética clássica muito distante - no espaço e no tempo — da realidade literária e cultural brasileira; por outro lado, refletem um tempo e um espaço - o Brasil do final do século XX - que são o tempo e o espaço vivenciados pelo autor. Ou seja, os poemas de Bueno expressam a retomada da tradição oriental e também a intertextualidade com a literatura moderna, em especial por meio da epifania, assim como as vivências de um brasileiro finissecular.

Em entrevista a Cláudio Daniel, Bueno fala da dificuldade em escrever os tankas e afirma que os considera sua sincera homenagem ao oriente:

No Pequeno tratado de brinquedos, você reuniu poemas que dialogam com a forma do tanka, o poema japonês de 5 versos, que é a gênese do haicai. Você pensa em publicar outros volumes de poesia?

Bueno - Não. Não tenho a menor intenção de publicar um novo livro de poesia estrito senso. O Pequeno tratado eu o considero a minha suma e a minha súmula. Desejei homenagear uma das nascentes da poesia - o Oriente, e foi o livro sobre o qual mais longo tempo trabalhei - um ano e meio para arrancar 58 tankas, apenas, de cinco versos cada um. E só Deus sabe com que sacrifício. Tenho ainda, inéditos, mais 25 tankas, num livrinho chamado Pincel de Kyoto, sobras do Pequeno tratado. Quem sabe, um dia, eu me incline a editá-lo. Mas repito - livro de poesia eu não penso para tão cedo. (BUENO, 2010, p. 3). 
Essa entrevista reporta, com clareza, a importância da cultura japonesa para Wilson Bueno e, ao mesmo tempo, a responsabilidade com que ele se dispôs a trabalhar uma poética nipônica. Bueno enfatiza que não foi tarefa simples alcançar a configuração da tradição milenar do tanka, mantendo a tradição e, ao mesmo tempo, transportá-la ao ocidente, de modo que se exprime a contemporaneidade do autor.

\section{Epifania: conceito}

De acordo com Moisés (2004, p. 156-157), epifania é originada do termo litúrgico que, posteriormente, teve uma transição para o circuito literário. Desse modo, podemos perceber que a palavra epifania abrange dois conceitos. Vejamos uma explicação sobre a visão litúrgica da epifania:

A palavra epifania (do Grego epiphaneia: apresentação, aparição) é empregada pelo calendário litúrgico da Igreja, para designar a apresentação de Jesus Cristo aos povos. Isso se deu com o conhecido episódio da visita dos Reis Magos ao Menino Jesus. E, com a reforma do citado calendário em 1999, após o Concílio Vaticano $2^{\circ}$, a Igreja transferiu essa festa litúrgica para o $2^{\circ}$ domingo depois do Natal, a qual é festivamente comemorada pelos congadeiros, com suas belas folias de reis. (CHAVES, 2003, p. 1).

O termo é aplicado quando um pensamento inspirado acontece de forma iluminadora, que parece revelação de origem divina. Como verbete, encontramos, no dicionário, o seguinte significado: "Aparição ou manifestação divina" (FERREIRA, 1988, p. 256), O que poderia ser uma explicação mais lógica e definitiva. Entretanto a palavra, tornada conceito literário, tem sido utilizada como uma técnica na arte de escrever textos.

Nesse sentido, a epifania - sem qualquer evidência da igreja católica ou de ato litúrgico - é conceito que ganhou grande destaque na obra de James Joyce, sendo um dos pontos centrais de sua concepção artística. Temos as seguintes observações sobre o conceito de epifania em James Joyce:

"Epifanias" corresponde a uma sua proposta técnica de escrita e constitui
objeto de estudo e debate por parte de literatos e aficcionados da arte. Seu
caráter singular, seu feitio de surpresa e nonsense despertaram a atenção da
Psicanálise, através da abordagem feita por Lacan no Seminário XXIII, "Le
Sinthome".
Em "Stephen Hero" Joyce diz que suas epifanias correspondem a: Uma
manifestação súbita, quer na vulgaridade do discurso ou do gesto, ou em
uma fase memorável da própria mente. Ele acreditava que cabia ao homem
de letras registrarem estas epifanias com cuidado extremo, visto que elas
mesmas são os momentos mais delicados e evanescentes. (AZEVEDO,
2004, p. 1).

A técnica proposta por Joyce é uma narrativa em cujo cenário os objetos ou o diálogo entre as personagens ilumina o pensamento do protagonista; essa revelação, que é a apreensão da realidade em sua integridade, em suas partes e em uma verdade subitamente descoberta é a epifania: 
Para tecer sua escrita, Joyce dizia seguir as categorias do belo ou categorias de apreensão do objeto, a estética de S. Tomaz de Aquino. Categorias essas que são: a integritas, a consonantia e a claritas.

"Este é o momento que eu chamo de epifania". "Primeiro reconhecemos que o objeto é uma coisa integral (integritas), em seguida reconhecemos que é uma estrutura composta organizada (consonantia), na verdade uma coisa; finalmente, quando a relação das partes é aprimorada ... reconhecemos que é a coisa que ela é [claritas]. Sua alma, seu quê próprio salta para nós das vestes de sua aparência. A alma do objeto mais comum, cuja estrutura está tão ajustada, parece-nos radiosa. O objeto realiza sua epifania". (AZEVEDO, 2004, p. 3, negritos no original; o parágrafo entre aspas é citação do Retrato do artista quando jovem, romance de Joyce).

Essas categorias acima descritas, no sentido epifânico, utilizadas por alguns escritores, têm formulações diferenciadas mediante a forma de escreverem suas obras. No Brasil, temos alguns autores que trabalham utilizando essa técnica, como Luiz Vilela, ao modo joyceano (cf. FRANJOTTI, 2011), e Clarice Lispector, em outra formulação (ver FERREIRA, 2003).

Em Wilson Bueno, apesar de ter o mesmo sentido da estética de S. Tomaz de Aquino, temos um tipo de epifania diferente desses autores. O poeta afirma que suas poesias foram gestadas no ato da iluminação ou revelação, no próprio ato epifânico. O que instiga nessa revelação de Wilson Bueno, diante da epifania, é a informação de que ele produz seus poemas dentro dessa experiência reveladora. Ele mesmo afirma que suas poesias foram construídas ao ter sido iluminado epifanicamente:

[os poemas de Pincel de Kyoto] se não alcançaram chegar à melhor poesia, [espero que] tenham traduzido ao menos a epifania com que foram gestados nas noites profundas do arrabalde. (BUENO, 2008, p. 13).

Em entrevista a Cláudio Daniel, Wilson Bueno esclarece essa questão da epifania, em suas obras poéticas, nos seguintes termos:

A sua prosa de ficção utiliza recursos do texto poético, como os jogos sonoros, imagens de alto impacto e invenções de linguagem, resultando em esmeraldas vivas. Qual é a fronteira entre prosa e poesia? Bueno - Tudo é a arte da poética, a meu ver. Escrevo assim, sempre escrevi assim. Não sei escrever sem ser íntimo. A prosa retém a poesia e é por ela gerada, num processo que aspira, antes de tudo, a ser livre. Acho que a literatura pode ser o máximo de liberdade que desfrutamos sobre a Terra - e eu quero amar o amor da escrita, o gozo epifânico de sua irradiação. Eu não consigo escrever dividido, amarrado pelo cânone e pela norma. Ora, se aquilo ali é o meu mais exasperado espaço de liberdade, é nele que devo me pôr a vigir. E tudo é a poesia das coisas. Viver já é um ato poético em si, para lembrar Hölderlin. E, dos atos poéticos, o que, convenhamos, requer de nós mais coragem, bravura, heroísmo - chame do que se quiser chamar ao desassombro. Indispensável para que sobrevivamos à perplexidade de nos flagrarmos vivos. (BUENO, 2000, p. 2).

Considerando a entrevista, observa-se que Bueno era intenso. Em suas obras, entregava-se de corpo e alma e com "gozo epifanico". Isso vem ao encontro da explicação de 
Ronaldo Vinagre Franjotti sobre a forma de escrita de autores que se destacaram com novas técnicas na arte literária:

Joyce é uma figura singularíssima do mundo literário, um dos poucos que consegue fugir dos esquemas e padrões que os literatos sempre tentam impor aos autores de renome. Ele e outros autores como Marcel Proust, Virginia Wolf, representam uma guinada na literatura no século passado; de seus escritos surge, por exemplo, a "corrente de consciência", método no qual o autor registra o movimento do pensamento, das sensações e sentimentos no espírito de seus personagens, sempre no plano da realidade cotidiana [...]. (FRANJOTTI, 2011, p. 61).

Acreditamos que os tankas são essencialmente construídos dessa forma, ou seja, dentro de uma "corrente de consciência" que se torna, posteriormente, um ato epifânico. Wilson Bueno registra em seus tankas, diante da epifania, momentos que passam pelo seu pensamento, num instante de revelação, ao apreender um objeto, uma imagem vista por ele em situações da vida cotidiana. São situações aparentemente comuns, mas que abrangem uma amplitude maior quando reveladas como algo ainda não visto e não pensado.

Diferentemente das epifanias encontradas nas obras de Luiz Vilela e James Joyce, o momento epifânico das poesias de Wilson Bueno não se encontra no diálogo das personagens de um romance, pois a revelação súbita aqui encontrada se passa unicamente na subjetividade do eu lírico.

Há, entretanto, no universo literário, ao menos dois tipos de epifania:

[...] podemos dividir dois tipos de epifania, visto que as mesmas derivam de tipos diferentes de apreensão estética: a primeira, no âmbito temporal (auditiva), é dialógica, dada pela palavra; a segunda, no âmbito do espaço (visual). É imagética, dada pela imagem [...]. (FRANJOTTI, 2011, p. 63).

Seguindo essa esteira de pensamento, parece-nos que as epifanias de Bueno são basicamente de âmbito visual. Ele faz a apreensão da imagem, daquilo que vê ou observa e, a partir daí, constrói suas epifanias. Expomos esse processo a seguir.

\section{A epifania em Pincel de Kyoto}

Os tankas de Wilson Bueno, segundo a concepção do autor, são registros momentâneos de alguma sensação ou um fragmento do dia a dia a partir de fatos comuns e simples vivenciados pelo ser humano; em outras palavras, são experiências epifânicas de instantes corriqueiros do cotidiano. Assim, ao que parece, a diferença entre a construção do tanka tradicional e a técnica epifânica utilizada por James Joyce e Luiz Vilela é pequena; entretanto, se aprofundarmos essas questões, veremos que os tankas epifânicas de Bueno transfiguram a forma de se construir os poemas japoneses, pelos seguintes motivos:

1. na constituição da forma poética do Japão, não se percebem traços de categorias da estética de S. Tomaz de Aquino;

2. no tanka japonês, não existe nada similar ao que define, para Joyce, o conceito de epifania;

3. no tanka original, o sujeito enunciador tende a se eclipsar, o que é característica da poética nipônica, enquanto, na lírica ocidental, há uma 
prevalência do eu lírico - e Wilson Bueno une, embora pareça paradoxal, as duas possibilidades em um mesmo poema.

Em suma, o tanka tradicional tem todo um conjunto de apreensão de objetos que registra um determinado momento, uma determinada emoção, uma determinada lembrança do passado ao observar alguma coisa no presente, mas não tem uma revelação, o "estalo" da epifania. Wilson Bueno soube unir essas diferenças, construindo tankas com epifania.

Vejamos alguns exemplos dessa apreensão epifânica do objeto:

\author{
calendário \\ as mãos de meu pai \\ nelas as veias de ontem \\ já falam dos anos \\ hoje era amanhã tão longe \\ sapatos de um velho monge.
}

(BUENO, p. 19).

No primeiro verso, temos a imagem de uma mão. No segundo, por animização, suas veias salientes e azuladas contrastam com a pele envelhecida e pregueada, sinal de sua idade. Na segunda estrofe, o verbo ser, no pretérito imperfeito, reforça a ação do tempo, ação ainda em execução: o presente sempre em busca de um futuro que se põe tão distante: nosso viver constitui esta busca. Por isso, o verbo está no pretérito imperfeito, indiciando a busca que nunca se conclui. O terceiro verso, ao mencionar as palavras sapatos e monge, dá uma ideia de algo velho, roto, pobre, humilde, resignado com a ação do tempo. É pertinente também observar que o título do poema confirma essa observação, pois, de acordo com o dicionário Aurélio, calendário significa "Folha impressa ou folheto onde se indicam os dias, semanas e meses do ano, as fases da Lua, as festas religiosas e os feriados nacionais" (FERREIRA, 1988, p. 118). O verbete tem sua maior ênfase, pois, na questão da idade e do tempo que se processa com suas marcas no próprio físico do sujeito, do eu enunciador.

O momento de epifania se dá quando o autor olha nas mãos do pai e se dá conta da velhice, do tempo que passa e, de repente, vê as marcas do tempo instalada no físico do homem que já não é mais o mesmo de outrora.

Vejamos outro tanka:

\title{
conversa
}

subúrbio anoitece

quantos postes, noite, teces

daqui até Osasco?

sonora uma onda de rádio

segreda que, noite, passas

(BUENO, 2008, p. 29). 
$\mathrm{O}$ enunciador fornece elementos para que se perceba o sentimento de solidão do motorista no momento em que viaja sozinho para Osasco. O poema retrata esse momento de solidão nos versos "subúrbio anoitece" e "quantos postes, noite, teces": é noite, a viagem é longa e tem por companhia apenas "sonora [...] onda de rádio" que o acompanha na "noite", [sendo a noite um tu que] "passas".

$\mathrm{O}$ enunciador revela a sua iluminação: viaja à noite, está sozinho quando mostra o objeto (poste) na noite, e são vários postes até chegar a Osasco, como se o motorista estivesse cansado, mesmo fadigado pela solidão e o contar dos postes fosse uma forma de aliviar a monotonia da viagem, ao mesmo tempo em que indica a longa jornada: o espaço torna-se claritas, tempo - a longa distância é tempo subjetivamente infinito.

Subentende-se a presença do sujeito (motorista). Nesse momento, o poeta parece nos revelar que o "motorista" está indo sozinho até Osasco, tendo como companhia o rádio (outro objeto associado ao sujeito - o motorista, o eu lírico).

Os elementos que o poema manipula são explicitados: o motorista está viajando sozinho - a partir desse momento de iluminação em que percebe sua solidão, esta é revelada, iluminada através dos postes que passam, da noite solitária e do rádio como sendo seus únicos companheiros. A noite torna-se uma metáfora tecida pela vida e a epifania dessa "conversa" (título do poema) é de que tal noite passa e se encerra, nem que seja pela "onda de rádio", ou seja, o viajante não está sozinho como "aparentemente" parece estar. A epifania é um segredo imaterial que se concretiza pela descoberta.

Outro exemplo:

$$
\begin{aligned}
& \text { cenário } \\
& \text { subúrbio anoitece } \\
& \text { quieta chuva das esquinas } \\
& \text { sobre os curvos postes } \\
& \text { o mistério das sombrinhas } \\
& \text { cor da noite na neblina }
\end{aligned}
$$

(BUENO, 2008, p. 26).

Nesse tanka, há a percepção de alguém que aprecia a noite chuvosa do subúrbio. Alguém está sozinho, e, naquele momento de solidão, o eu poético reflete sobre o cenário em que se encontra: o "subúrbio anoitece/quieta chuva das esquivas".

Tem-se a impressão de que, no momento em que o observador vê a chuva cair lentamente sobre os postes e, na bruma, as sombrinhas (objetos), a epifania o ilumina. Em termos literais, o eu lírico observa a chuva e a noite e constata, nessa atmosfera, o cenário do subúrbio, no qual os objetos, como os postes e as pessoas, protegem-se da chuva com sombrinhas, que, embora sempre coloridas no referente do cotidiano, aqui surgem apenas na "cor da noite".

De início, o observante se revela também uma pessoa solitária em uma noite chuvosa, calma, tranquila, ma,s ao mesmo tempo, dá-se um sentido de igualdade, de solidariedade, pois ele se irmana com o outro, desconhecido na multidão sem rosto, representado pelas "sombrinhas".

Vejamos outro tanka:

\section{exatidão}


manhã impossível de feltro os azuis do céu tocados de sinos

fosse assim a vida sempre cadê que havia o poente?

(BUENO, 2008, p. 36).

Nesse texto, percebe-se que o enunciador cria um tanka sereno, suave que revela sua epifania no movimento de comunhão expresso pelos versos "de feltro os azuis do céu/fosse assim a vida sempre".

O locutor reproduz sua iluminação quando imagina que o céu está radiante no momento único, em ocasião de alegria, de ostentação, que acontece no instante em que os sinos tocam. O enunciador deseja que a vida seja sempre festiva, alegre, querendo que a "paz" sentida por ele, representada pelos sinos que tocam, fosse eterna.

Em um primeiro momento, parece que o eu lírico, através de seu tanka "exatidão", mostra a eucaristia do ato de iluminar, querendo que aquele momento de harmonia "fosse assim a vida sempre", ou seja, tem-se a sensação de que a vida é bela, extraordinária, e o cenário nos dá um momento exato, único, se não fosse dizimado pelo fim pelo poente: "cadê que havia poente?". No entanto o sol haverá de nascer novamente porque, se o tempo parar, não haverá mais o pôr do sol. A graça está verdadeiramente na variedade da vida.

\section{Vejamos a epifania em outro tanka:}

noturno

os cães do subúrbio

os silêncios acham dúbios

e por isso uivam

antes não cantem nem dancem

do que saber que eles mugem

(BUENO, 2008, p. 17).

Nesse tanka, a revelação epifânica se dá quando o expositor escuta, no silêncio da noite, pois o título é uma referência a que o episódio da iluminação acontece ao anoitecer, o barulho dos cães uivando no subúrbio.

O eu lírico problematiza a lamentação dos cães uivarem no silêncio incerto da hora. Não se interessa em saber o motivo por que os cães não cantam nem dança,. Ou seja, melhor seria que os cães dançassem ou cantassem do que mugissem. Os cães uivam porque percebem o silêncio da noite e se sentem inseguros diante do sossego. Ao perceber isso, o eu lírico apreende esse momento e o descreve em forma poética. A revelação final é de que os cachorros, representando o próprio eu lírico, buscam a "exatidão" (título de um poema de que já tratamos), fogem do "dúbio" e da solidão. Pois os cães isolados no "cenário" (título de outro poema já visto aqui) amplo da noite se irmanam pelo uivo, porque, com o seu uivo participativo, que rompe a noite (espaço de fraternidade, como vimos no tanka "cenário"), é a negação do espírito passivo, bovino, sem questionamento, próprio daqueles que "mugem". 
CASA, Vol.9 n.2, dezembro de 2011

\section{A epifania em Pequeno tratado de brinquedos}

Do livro Pequeno tratado de brinquedos (lembrando que esse volume, de 1996, antecede em doze anos o segundo livro de tankas de Wilson Bueno), faremos análise de dois tankas que homologam a leitura que propomos para os poemas do Pincel de Kyoto (2008).

Vejamos o primeiro exemplo:

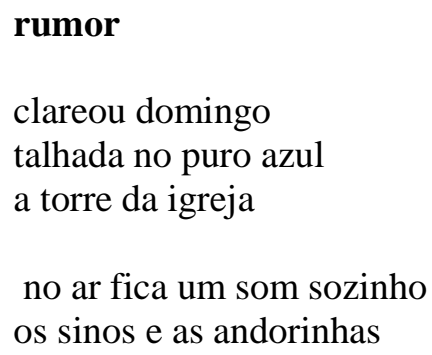

(BUENO, 1996, p. 21).

O tanka "rumor" revela um momento em que o enunciador observa um instante esplendoroso, de cima da torre de igreja, "talhada no puro azul". A epifania revela-se no momento em que o poeta observa que, no amanhecer, "clareou domingo" e o dia estava lindo, com o céu azul.

Os detalhes de uma manhã de domingo, ao som de sinos, e a observação da claridade [do sol] "talhada no puro azul" [do céu] fazem com que o eu lírico vivencie um instante de paz, serenidade.

Nesse poema percebemos que, ao contrário do tanka japonês, está evidente a presença do eu lírico em sua subjetividade, pois o adjetivo puro instaura o eu no cerne da cena. É possível constatar que, diferentemente dos tankas nipônicos, há traços da estética de S. Tomaz de Aquino. Primeiro, temos o reconhecimento de objetos (integritas): a cor do céu, azul, a torre, o sino, as andorinhas; em seguida, há a apreensão desses objetos em conjunto e organização (consonantia); por fim, o incognoscível se revela (claritas) - uma revelação, a epifania. E, assim, aquela manhã de domingo, que, mesmo sendo bela e agradável, "parecia" solitária, contém melodias, "no ar fica um som", e seres, "as andorinhas", com o que o universo se mostra sem solidão e sem o pressentido vazio inicial.

Vejamos mais um exemplo:

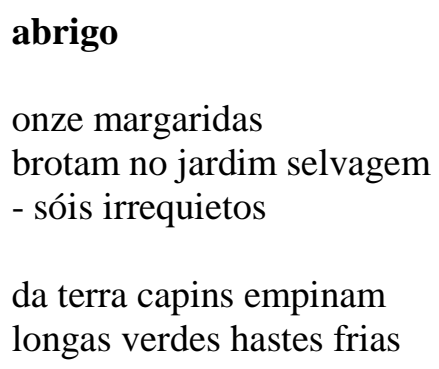

(BUENO, 1996, p.17).

Nesse tanka, o eu lírico mostra um momento de reflexão ao observar as onze margaridas que "brotam no jardim selvagem". O momento epifânico está na percepção de esquecimento e isolamento em que as margaridas estão, uma vez que elas brotam em local inadequado para elas, o "jardim selvagem". 
As margaridas estão sem abrigo, no meio "da terra de capins", mas deveriam estar no meio de flores, rosas que exalam perfumes. No "jardim selvagem", no qual "capins empinam / longas verdes hastes frias", brotam as margaridas

Nesse tanka, o enunciador percebe o momento epifânico por intermédio da percepção ou da revelação de que as onze margaridas, mesmo estando juntas e tendo por "abrigo" o "jardim selvagem", brotam. Brotam mesmo estando fora de seu lugar correto, ou seja, o objeto margarida encontra-se fora do seu habitat natural, do seu mundo, de seu jardim, e encontra-se em um lugar selvagem. Nesse momento, o observante encontra a iluminação, a revelação do isolamento das onze margaridas que brotam juntas, isolamento pelo fato de não estarem com as demais flores do jardim. As margaridas podem representar o próprio ser humano, no mundo selvagem, ou seja, a margarida se solidariza com o outro.

Uma epifania está na descoberta em oposição: sol versus frio — "sóis irrequietos" versus "hastes frias" é outra epifania. No eixo paradigmático do sol, estão as margaridas, o jardim selvagem, a inquietude; no eixo do frio está o capim, figurativizado com suas hastes longas que saem do chão, é inumerável, selvagem, e vencem um meio hostil; as margaridas, irrequietas, medidas, brotam nesse universo - e a claritas do enunciador (que tende à ausência nipônica, mas que se manifesta pelos adjetivos) é de que o mundo selvagem é o seu abrigo.

\section{Conclusão}

O que nos parece é que as epifanias de Wilson Bueno, tal como as desvelamos ao longo de nossa leitura, é a "manifestação súbita" de uma realidade compartilhada por muitos em vários momentos e em diferentes circunstâncias da vida. A comunhão, embora dentro do sistema da complexidade do ser, entre todos é um sinal de igualdade, ou seja, muitos de nós estamos sós no meio da multidão compartilhando de um mesmo instante de solidão. Estamos sós, mas juntos.

As epifanias de Bueno nos revelam muitos seres humanos que, por algum motivo, encontram-se em um determinado momento e lugar e vivenciam solidários do mesmo sentimento da solidão, mas com cada qual vivendo em seu mundo.

Bueno transfigura o tanka japonês do oriente, misturando-o com atos epifânicos (técnica artística literária do ocidente) e com manifestações de sua própria consciência, de sua própria angústia, de visões e "aparições" que, de certa forma, são "fantasmas" que perseguem toda a humanidade. Por isso, seus poemas tornam-se algo que pode ser dividido e sentido por todos nós: os tankas de Wilson Bueno foram criados no final do século XX, em uma região do Brasil, a partir da concepção dos tankas tradicionais feitos no Japão, com temas do homem em todos os tempos, em linguagem que tem por base a tradição e que renova essa tradição ao incorporar estratégias literárias ocidentais, de modo que o resultado é uma obra com o perene e o novo, com o cotidiano próximo e a pulsação da lírica secular nipônica. Desse modo, os tankas de Wilson Bueno alcançam uma expressão universal.

Podemos concluir também que, diferentemente dos outros autores que trabalham ou trabalharam experiências epifânicas, Wilson Bueno aplica uma forma nova de utilizar a epifania, pois esta, que geralmente, nos contos ou romances, descreve a apreensão da significação de um determinado objeto, é revelada ao personagem e, às vezes, apenas ao leitor, enquanto que, nos poemas tankas de Wilson Bueno, a epifania já se deu como claritas ao próprio enunciatário, ou seja, precede sua transformação em discurso. Dessa forma, essa inquieta construção epifânica de Wilson Bueno se apresenta como inovadora do gênero lírico na literatura contemporânea brasileira. 
CASA, Vol.9 n.2, dezembro de 2011

\section{REFERÊNCIAS}

AZEVEDO, Lúcia. James Joyce e suas epifanias. Cogito, 2004, vol. Disponível em: $<$ http://pepsic.bvsalud.org/scielo.php?script=sci_arttext\&pid=S1519-94792004000100033 >. Acesso em 20 jun. 2011.

BUENO, Wilson. Pincel de Kyoto. São Paulo: Lumme, 2008.

, Wilson. Pequeno tratado de brinquedos. Curitiba: Iluminuras, 1996.

, Wilson. Entrevista com Wilson Bueno. A Garganta da Serpente, 2002. Entrevista concedida a Rodrigo de Souza Leão. Disponível em: <http://www.gargantadaserpente .com/entrevista/wilsonbueno.shtml > . Acesso em 06 abr. 2011.

Wilson. Entrevista. Disponível em: 〈www.cartunistasolda.blogspot.com>. Acesso em 23 maio 2009.

Wilson. Uma conversa com Wilson Bueno. Suplemento Literário do Minas Gerais, 2000. Disponível em: 〈http://www.cronopios.com.br/site/artigos.asp?id=4594>. Acesso em 05 abr. 2011. Entrevista concedida a Cláudio Daniel.

CARVALHO, Ana Paula. Policia do Paraná diz que escritor Wilson Bueno pode ter sido vítima de latrocínio. Extras, notícia, O globo. Disponível em:

$<$ http://extra.globo.com/noticias/brasil /policia -do-parana-diz-que-escritor-wilson-buenopode-ter-sido-vitima-de-latrocinio-136406.html>. Acesso em 29 maio 2011.

CHAVES, José. Epifania. Portal do espírito, 6 maio 2003. Disponível em < www.espirito .org.br/portal/artigos/josé-chaves/epifania.html>. Acesso em 20 maio 2011.

FERREIRA, Aurélio Buarque de Holanda. Dicionário Aurélio Básico da Língua Portuguesa. Rio de Janeiro: Nova fronteira, 1988.

FERREIRA, Fernanda silva. A construção da epifania nas narrativas de Clarice Lispector. Todas as letras, Mackenzie, 2003. Disponível em: <http://www.mackenzie.br/fileadmin /Graduacao/CCL/projeto_todasasletras/inicie/FernandaFerreira.pdf>. Acesso em 29 abr. 2011.

FRANCHETTI, Paulo. DOI, T. Elza \& DANTAS, Luiz. Haikai: antologia e história. 3. ed. Campinas: Unicamp, 1996.

FRANJOTTI, Ronaldo Vinagre. O mundo como GRAÇA e representação: epifania, polifonia e niilismo em Luiz Vilela. Campo Grande, 2011, 123 fls. Dissertação (Mestrado, Estudos de Linguagens), UFMS. Orientador: Rauer Ribeiro Rodrigues. Disponível em: <http://gpluizvilela.blogspot.com/p/fortuna-critica.html>. Acesso em 16 abr. 2011.

KUBOTA, Marília. A transfiguração do Tanka. Jornal de letras e artes japonesas Memai. Entrevista. Disponível em: <www.cartunistasolda.blogspot.com>. Acesso em 23 maio 2009.

LIMA, Ricardo. A copista de Wilson Bueno. Germina, dez. 2007. Disponível em: <http://.germinaliteratura.com.br/livro>. Acesso em 23 maio 2009.

MOISÉS, Massaud. Dicionários de termos literários. 12. ed. São Paulo: Cultrix, 2004.

OLIVEIRA, Geovania Quinalha. Reescrever-te a ti nem sei se com carícias: as várias reescrituras no romance Amar te a ti nem sei se com carícias, de Wilson Bueno. Três Lagoas, MS, 2009. Dissertação (Mestrado, Letras, Estudos Literários), UFMS. Disponível em: <http://posgraduacaoletras.com.br/ufms/dissertacoes/>. Acesso em 20 maio 2011. 
CASA, Vol.9 n.2, dezembro de 2011

RODRIGUES, Rauer Ribeiro. O intertexto de Wilson Bueno em A copista de Kafka.

Itinerários, n. 28, p. 235-237, jan.-jun. 2009. Disponível em:

<www.seer.fclar.unesp.br/itinerarios/article/download/2154/1772>. Acesso em 2 jun. 2011.

Disponível também em: 〈http://migre.me/5P5wf $>$. Acesso em 2 jun. 2011.

Recebido em: 16.07 .11

Aprovado em: 11.09.11 